outside these streams, or in their possible, but not actual, extension.

Having stated that he was prepared to give, in another paper on the origin of the disease which he was preparing, an ample explanation of some well-known points about cholera ; such as its partial connection with the east wind, its following the course of large rivers, its greater prevalence on tertiary strata, alluvial tracts, and the deltas of rivers, and its comparative rarity on secondary and primary strata, the author proceeded: "It was not my intention at the present time to enter into the question of the origin of the disease; but having read a few days ago that Dr. Buchanan in this very hall congratulated the meeting on being able to number among the things of the past the time when the propagation of cholera was supposed to be due to all manner of cosmic and atmospheric influences, and on having "reached a solid basis of fact and knowledge upon which further observation might be built with security,' I am tempted to declare that I for one maintain that this despised theory, which Dr. Buchanan fancies is buried and put out of sight, is the correct one. I maintain that cosmic influence lies at the origin of cholera-that cholera is intimately connected with auroral displays and with solar disturbances. I believe that I am able to show that a remarkable connection exists between the maxima and the minima of cholera epidemics and of solar spots; and in directing your attention to this map, on which I have represented graphically the amount of cholera and the number of sun-spots for the last fifty years, I wish to show that there is here also ' $a$ solid basis of fact and knowledge upon which further observation might be built with security.' You are all probably aware that the great astronomer Schwabe discovered that the sun-spots have what is called a ten-year period ; that is, there is a minimum of spots every ten years. It was also discovered that the diurnal variation in the amount of declination of the magnetic needle has a ten.year period. The same was proved in regard to earth currents, and also auroræ. The maxima and minima of the four were found to be contemporaneous. This was a great result; but Professor Woli, on tabulating all the sun-spots from the year I6II, discovered that the period was not ten years, but II'II years. This period is now the accepted one for the sun-spots, and it has been established for the magnetic declination, and by Wolf for the auroræ. Now, it is a curious fact that the last year of every century; as I 800 , has a minimum of sun-spots, so that the minima are $1800, \mathrm{I} 8 \mathrm{III}^{\circ} \mathrm{I}, 1822^{\prime} 22, \mathrm{I} 833^{\circ} 33^{2}, \& \mathrm{c}$. The maxima do not lie midway between the minima, but anticipate it by falling on the year 477 after a minimum; for example, 1800 was a minimum year, then 180477 was a maximum year. Now, cholera epidemics have, I believe, a period equal to a period and a half of sun-spots. Reckoning then from 1800 , we get as a period and a half the date I 816.66 , which was shortly before the great Indian outbreak; another period and a half gives $1833^{\prime} 33$, a year in which there was a maximum of cholera; another, I $849^{\circ} 99$, that is, 1850 , a year having a maximum of cholera; another, I 866.66 , a year having a maximum of cholera; another, $1883^{\circ} 33$, as the year in which there will be a cholera maximum. It follows from what has been already said that $1783^{\circ} 33$ would be a year in which cholera was at a maximum. Now it is a fact that in April I 783 there was a great outbreak of the disease at Hurdwar.

"I would call attention to the parallelism of increase and decrease of these curves. I am not, however, prepared to say that sun-spots originate cholera; for they may both be the effects of some other cause, which may indeed be the action of the other planets upon the earth and upon the sun. If that be the case-and I see no reason why it should not-we may then have an explanation of the minor periods and of the large period of 56 years, which Wolf believes he has detected; and also of the minor periods observed in cholera-epidemics.
"My own opinion, derived from an investigation of the subject, is that each planet, in coming to and in going from perihelion-more especially about the time of the equinoxes-produces a violent action upon the sun, and has a violent sympathetic action produced within itselfinternally manifested by earthquakes, and externally by auroral displays and volcanic eruptions, such as that of Vesuvius at the present moment; in fact, just such an action as develops the tail of a comet when it is coming to and going from perihelion; and when two or more planets happen to be coming to or going from perihelion at the same time, and are in, or nearly in, the same line with the sun-being of course nearly in the same planethe combined violent action produces a maximum of sunspots, and in connection with it a maximum of cholera on the earth. The number of deaths from cholera in any year-for example, the deaths in Calcutta during the six years $1865-70$-increased as the earth passed from perihelion, especially after March $2 \mathrm{r}$, came to a minimum when it was in aphelion, and increased again when it passed to perihelion, and notably after equinoctial day; thus affording a fair test of my theory."

\section{ON THE DEPTHS OF WATER IN WHICH WAVES BREAK}

OBSERVATIONS MADE AT SCARBOROUGH IN I87O

$A S$ the force which different sea-works have to resist A varies with the height of the waves that reach the cozst line, any data which will enable the marine engineer to predict this height when designing such works must obviously be of importance. In the Edinburgh Philosophical fournal for July 1852 , I stated, as the result of experiments made in 1850 on a small fresh-water loch, and afterwards on larger sheets of water, that the height of the waves increased most nearly in the "ratio of the square root of their distances from the windward shore," or, in other words, the crest of the wave as it increases in height describes a parabolic curve. So that, if $h=$ height of wave, $d=$ distance, and $a$ is a coefficient varying with the strength of the wind, $h=a \sqrt{ } d$. For most practical purposes of the enoineer, the coefficient $a$ may for heavy gales be taken at one and a half; so that the formula becomes-

$$
h=\mathrm{I} \cdot 5 \sqrt{ } d
$$

where $h$ represents the height of the wave in feet, and $d=$ length of exposure in miles. $*$ As elsewhere stated, $f$ this formula becomes for short distances-say for under ten miles-

$$
h=1.5 \sqrt{d} d+(2.5-\sqrt[4]{ } d)
$$

The height of the wave, however, which reaches any particular work, is not necessarily that which is due to the line of exposure; for the shallowing of the water near the shore may cause the heaviest waves to break, either partially or wholly, before they reach the work. Mr. Leslie found that at Arbroath Harbour the works were not so severely tried by the very heaviest class of waves as by others of lesser size, which were not trippet up by the outlying rocks. The same effect has also been observed at the river Ain, where the smaller waves occasion a greater "range" in the harbour than the larger ones which break in passing over the bar, and are thus reduced in height. The larger waves are not, then, always so destructive as the smaller. It becomes, therefore, a question of some moment to determine the maximum height of wave that is possible in a given depth of water.

Mr. Scott Russell, whose contributions to what may be

* $\mathrm{M}_{\mathrm{r}}$. Hawkesley, in the "Proceedings of the Institute of Civil Engineers," gives a formula which is satisfactory so fat as it corrohorates the law of increase which I had stated in the Eainburg/t Pritosoplizcal foutnal in 1852; bat he employs a coefficient which gives much greater results than my experience warrants. t "The Design and Construction of Harbours," by Thomas Stevenson,
F.R.S.E. (Edinburgh, $x 86_{4}:$ p. 22). 
called the marine branch of hydrodynamics are of such great value, has stated that "he has never noticed a wave so much as Ioft. high in Ioft. water, nor so much as $20 \mathrm{ft}$. high in 20 ft. water, nor 3 oft. high in five fathoms water; but he has seen waves approach very nearly to those limits." $\mathrm{Mr}$. Russell has not stated whether the depths of water referred to are those below the trough of the sea or below the still-water level. In my book on "Harbours" I gave three observations on short waves from $2 \mathrm{ft}$. $6 \mathrm{in}$. to $3 \mathrm{ft}$. high, which corroborated Mr. Russell's statement, supposing him to refer to the depth below the hollow. But since that time I had an opportunity, during a N.E. swell in July 1870, of observing the depths in which waves of a larger class broke at the Promenade Pier at Scarborough, where the heights could be measured with very considerable accuracy on the iron piles and open sloping slip or grating at the seaward end of the pier; and the following are the results :-

Heights of waves from hollow to crest.

$$
\begin{array}{ll}
5 & 6 \\
5 & 0 \\
5 & 0 \\
5 & 6 \\
\hline 5 & 3
\end{array}=\text { mean height. }
$$

The mean depth of water below the trough was roft. 3 in.

Heights of the highest waves from hollow to crest.

$$
\begin{array}{ll}
6 & 0 \\
6 & 0 \\
8 & 0 \\
6 & 0 \\
6 & 0 \\
\hline 6 & 6
\end{array}
$$

The mean depth of water below the trough was $13 \mathrm{ft} .8 \frac{1}{2} \mathrm{in}$. So that in both cases those waves did not follow Mr. Russell's law, but broke when the depths below their tronghs were about twice iheir own height.

It must not be supposed, as is generally believed, that the height of the crest above the mean level of the sea is equal to the depression of the trough below that level; for Prof. Rankine has lately shown that this is not the case. When $L=$ length of wave, $H=$ height from trough to crest.

$$
\begin{aligned}
& \text { Crest above still water }=\frac{H}{2}+7854 \frac{H^{2}}{L} . \\
& \text { Trough below still water }=\frac{H}{2}-7854 \frac{H^{2}}{L} .
\end{aligned}
$$

These formulæ, he states, are exact only for water of considerable depth as compared with the wave's length. Edinburgh

THOMAS STEVENSON

\section{CYCLONES IN THE INDIAN OCEAN}

SEVERAL cyclones have passed Mauritius since the latter part of January. From the 24 th to the 3oth of that month the barometer at the Observatory fell from 29.888 to 29708 inches, with the wind squally from E. At IO A.M. on the 3 oth it was intimated to the newspapers that there were "indications of a hurricane approaching the island;" but at 2 P.M., the wind having in the interval veered to $\mathrm{N}$. of $\mathrm{E}$, it was announced that there was "little danger."

This storm was encountered by the schooner Emily, on her passage from Tamatave, from Jan. 29 to Feb. I. At the commencement of the gale, she was in $19^{\circ} 3 \mathrm{I}^{\prime} \mathrm{S}$., and $53^{\circ} 30^{\prime} \mathrm{E}$. The wind veered from N.E. to E., S.E., S., S.W., W., and N.W., with a "tremendous sea and torrents of rain," and the lowest reading of the barometer on board was $29^{\circ} 00$ inches. The vessel escaped with the loss of only a few sails.

The storm then curved to the $\mathrm{S}$. and $\mathrm{E}$, and was experienced by the barques Gladiateur and Abbotsford on Feb. 2 and 3 , in $31^{\circ}$ to $29^{\circ} \mathrm{S}$, and $54^{\circ}$ to $55^{\circ} \mathrm{E}$. With the former vessel the wind veered from E. to N.E. and N., blowing at one time with great violence. The barometer at. 8 A.M. on the 2nd was at 28.80 , and the wind from E.N.E. The Abbotsford had the wind from the same direction, and her barometer was at 28.40 at 5 A.M. on the 2nd. Both vessels had a "tremendous sea and torrents of rain," and they lost sails and bulwarks.

On Feb. 5 the barometer at Mauritius, after rising to $29^{\circ} 790$, again began to fall, and on the 7 th was at $29^{\circ} 606$. The wind was squally from S.E., and it veered to S. by W., from which point there was a gentle breeze at $9.3^{\circ}$ P.M. on the 7 th, with fine clear weather.

At Io A.M. on the 7th it was announced that "the weather of the last two or three days indicated the passage of another storm, which then broke between E.N.E. and E. ;" and at Io A.M. on the following day that "the storm had curved to the S. and S.E."

This storm was encountered by the barque Elizabeth, from Melbourne to Mauritius, on the 7 th and 8th, in $20^{\circ} \mathrm{I} 6^{\prime} \mathrm{S}$., and $68^{\circ} \mathrm{E}$. The wind was strongest from E.N.E. to N.N.E., and the lowest barometer was $29^{\circ} 20$. There were "torrents of rain." By standing back to the E. the Elizabeth avoided all danger.

On Sunday, Feb. II, the barometer at the Observatory, after rising to $29^{\circ} 80$, again began to fall, with the wind squally from S.E., and the weather fine. During the 12 th it fell 060 inch, and 090 inch more during the 13 th, with the wind still squally from the same quarter. At Io A.M. on the i4th the following notice was sent to the newspapers:- "A hurricane since the IIth. It now bears about E.N.E. of us. There are some signs that it will pass to the $E$. and $S$. of the island, but there is dang€r." The barometer still falling, and the wind increasing to strong breezes from S. by E. to S.S.E, at 3 P.M. a telegram was sent to Port Louis (6 miles off), stating that "the centre of the hurricane was about 350 miles to the E.N.E., and approaching the island," and soon afterwards storm signals were hoisted at the railway stations. The barometer at 3 P.M. stood at $29^{\circ} 6 \mathrm{I} 2$, and the wind, which was then S. by E., was blowing with an estimated force of $2.5 \mathrm{lbs}$. on the square foot.

At 9 A.M. on the 15 th the barometer was at $29^{\circ} 478$, with a strong gale from S.E., and it was estimated and announced that the "centre of the storm bore about N.N.E. 150 to 200 miles, and that it was still approaching the island." At 3 P.M. the wind being from E.S.E. to E. by $\mathrm{S}$. in increasing gales, and the barometer at 29382 , it was telegraphed to Port Louis that "the centre was about I 50 miles to N. by $E$., and that it would probably pass, with an increase of wind, to N.W. and W. of the island, without doing much damage."

During the night the wind increased considerably from E.S.E. to E. by S., and the barometer attained its lowest reading $\left(29^{\circ} 328\right)$ at I A.M. on the I6th ; but the mercury was oscillating, being at 2 A.M. at $29^{\circ} 35^{6}$, and at 3 A.M. $29^{\prime} 330$; and the time of the greatest depression of the mercury, as shown by the barograph (at the Magnetic Observatory, three miles off) was 2.40 A.M. At 9 A.M. the barometer was at $29^{\circ} 440$, with the wind at E. to E. by N., and it was announced that "the centre bore N.N.W., and that there was no danger."

The barometer then continued to rise, until, at noon on the 18 th, it was at 29.882 , with a moderate breeze from N.E.

It is worthy of remark that the wind never went beyond N.N.E., but gradually backed to East.

This storm was more or less encountered at sea by the Harpesia, Gryfe, Oleander, St. Germaine, Misser, $S . S$. 